\title{
SIMPBOARD -A MONGODB IMPLEMENTATION OF A SIMPLIFIED ONLINE BULLETIN BOARD SYSTEM FOR INFORMATION DISSEMINATION IN TERTIARY INSTITUTIONS
}

\author{
A. E. Ibor ${ }^{1,}$, K. E. Eyong ${ }^{2}$ and E. B. Edim ${ }^{3}$

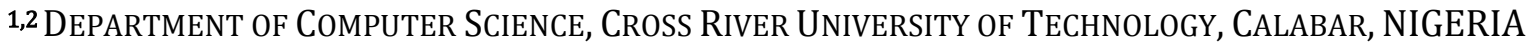 \\ 3 Department of Computer Science, University of Calabar, Calabar, Cross River State. NiGERIA \\ Email addresses: 1 ayei.ibor@gmail.com, 2 kebeeyong@gmail.com, 3 etore8522@gmail.com
}

\begin{abstract}
Information dissemination is a key concern for most tertiary institutions. While information is relevant for the day-to-day running of a tertiary institution, the rightful information, sometimes, is not available for the appropriate decisions to be taken. The practice, in some institutions, is the use of wooden notice boards for making information available to the academic community. In many cases, such means of information broadcasting has been found to be inefficient, and largely a component of physical presence. However, electronic presence is becoming more and more acceptable for spreading information. To this effect, this paper will discuss the design and implementation of a simplified online bulletin board system called SIMPBOARD that can be accessed through the web browser of a computer or smart phone. Furthermore, the system will allow for anywhere access to bulletins, and possible archiving of same, for reference purposes, through the use of Mongo DB with Meteor JS Framework.
\end{abstract}

Keywords: information exchange, bulletin board, electronic presence, computer-mediated communication, MongoDB

\section{INTRODUCTION}

One of the most important needs of this age is concise, good, valid and timely information. In most tertiary institutions in Nigeria, for instance, the information unit, is most times, responsible for disseminating information such as announcements, events, lecture and examination schedules, and other reminders from the school management to the academic community. This is sometimes done through notice boards found at various faculties, departments and strategic areas in the institution.

However, the manual method being employed suffers a number of setbacks. Information on notice boards can be distorted, lost and/or destroyed. This information can also be subject to harsh weather conditions like rain and dust as well as conflicts or students' protest, in which case, vital information on paper sheets is likely to be destroyed or degraded. Though backup paper copies may exist, such copies may never be made available to the teeming populace of the institution for reference purposes when destroyed. To this effect, it is pertinent to deploy a system of information dissemination that can be implemented online over a computer network (such as the internet) to enable users to post, read, and download information such as bulletins, videos and audio messages.
According to [11], the use of electronic bulletin boards allow for the easy exchange of digital contents over opportunistic wireless networks. This information exchange is significant for the students and staff in any tertiary institution as it provides the avenue for fair interactions and assessment of policies that govern the overall success of the institution. Similarly, [8] discussed that computer-mediated communications are suitable for collaborative learning while enhancing interactions among peers. These interactions are necessary for information flow within a tertiary institution.

Furthermore, with SIMPBOARD, information can be assessed on-the-go rather than standing in long queues or crowds waiting to have access to bulletins on wooden notice boards. This paper bridges the existing communication gap in information dissemination in most tertiary institutions through a web application that will allow for easy access to information at anytime and anywhere.

\section{REVIEW OF RELATED LITERATURE}

Bulletin boards also called pin or notice boards are surfaces used basically for the posting of messages that require public attention. These messages can be tailored towards providing information, announcing events and/or advertising products. As posited in [6], bulletin 
boards are based on asynchronous text-based computermediated communication (CMC). This method of communication is discussed in their work as providing the means to create, exchange and identify information using the network of telecommunication systems. The ability to create, exchange and identify information enhances social presence as discussed in [9].

Computer-mediated communication systems such as online bulletin boards are highly interactive. This system of communication merges the stable disposition of written communication with the speed and dynamism of spoken communication. This synergy creates a platform for quick access to digital contents and the tendency to take decisions in real time. In [12], it is claimed that the use of bulletin board systems allow for the merging of messages into a list that can be accessed and approved by one or more participants. This enhancement in information sharing creates convenience for the consumers of the information in terms of implementation and reuse.

According to [2], asynchronous text-based communication such as bulletin boards and email are relevant for a lot of reasons. One of such reasons is that they contribute to cognitive and affective outcomes in information exchange among people. Moreover, the target audience can be reached at long distances, and collaborative knowledge building as asserted by [4] is a possibility through the use of asynchronous text-based communication. Although [3] claim that online bulletin boards have not evolved significantly with the fast pace of development witnessed in the evolution of software systems, [13] believe that the ubiquitous nature of the Internet will likely allow for the emergence of computermediated communications such as online bulletin boards to evolve as veritable means of information exchange across professional, educational and interpersonal realms.

\section{DESIGN METHODOLOGY}

This section highlights the various components of the design of SIMPBOARD for effective information dissemination in a typical tertiary institution. A brief description of the proposed system and the interactions within its components is also presented. This necessitates the design of a new system that adopts an object-oriented design approach for describing its different design elements.

\subsection{The Proposed System}

SIMPBOARD develops a web-based bulletin board system for tertiary institutions. The system will provide a means for students and staff of any tertiary institution to conveniently access information with ease irrespective of their locations. The system enables: i. Notification of new bulletins to users as they are posted on the board.

ii. Access to information irrespective of the user's location at any given point in time.

iii. A database of all the information posted on the board.

iv. Access to concise and verifiable information.

v. Approvals of posts by an administrator to enhance the dissemination of reliable information

vi. User authentication for protected access to information.

\subsection{High level Model of the Proposed System}

This section identifies all the modules in the new system design and the relationship that exist between them. The high level model shows the logical order in the hierarchy of modules for input and output operations.

Figure 1 presents an overview of the entire system, identifies the main components of the SIMPBOARD web application and its various interfaces. The various functions of the main actors of the system including the Administrator, Staff and Students are depicted. While the staff and students can view posts such as announcements and events, and as well manage their personal settings, the administrator will be able to manage announcements, events, staff and students' profiles. Posts added to SIMPBOARD are censored and approved by the administrator before they are made accessible to the users (staff and students). This is to enhance the accuracy of the information presented before it is uploaded for public consumption. Similarly, the administrator can edit or delete posts at any point in time on SIMPBOARD.

\subsection{Use case diagram}

The use case diagram captures the dynamic behaviour of the system and defines the reaction of the elements of the system at its point of operation or execution. Modeling a system with static behaviour is not adequate. To this effect, [10] opines that a use case diagram comprises internal and external agents called actors. These actors are used to model the behaviour of the system as viewed by an external observer. Therefore, the diagram depicts the system including the subsystem of an application, in order to capture the different functionalities of the system dynamically. Figure 2 shows the use case diagram of the SIMPBOARD system wherein one can see the different actors and their use cases for the system.

\subsection{Activity Diagram}

Figures 3 and 4 show the activity diagrams of the SIMPBOARD application. 


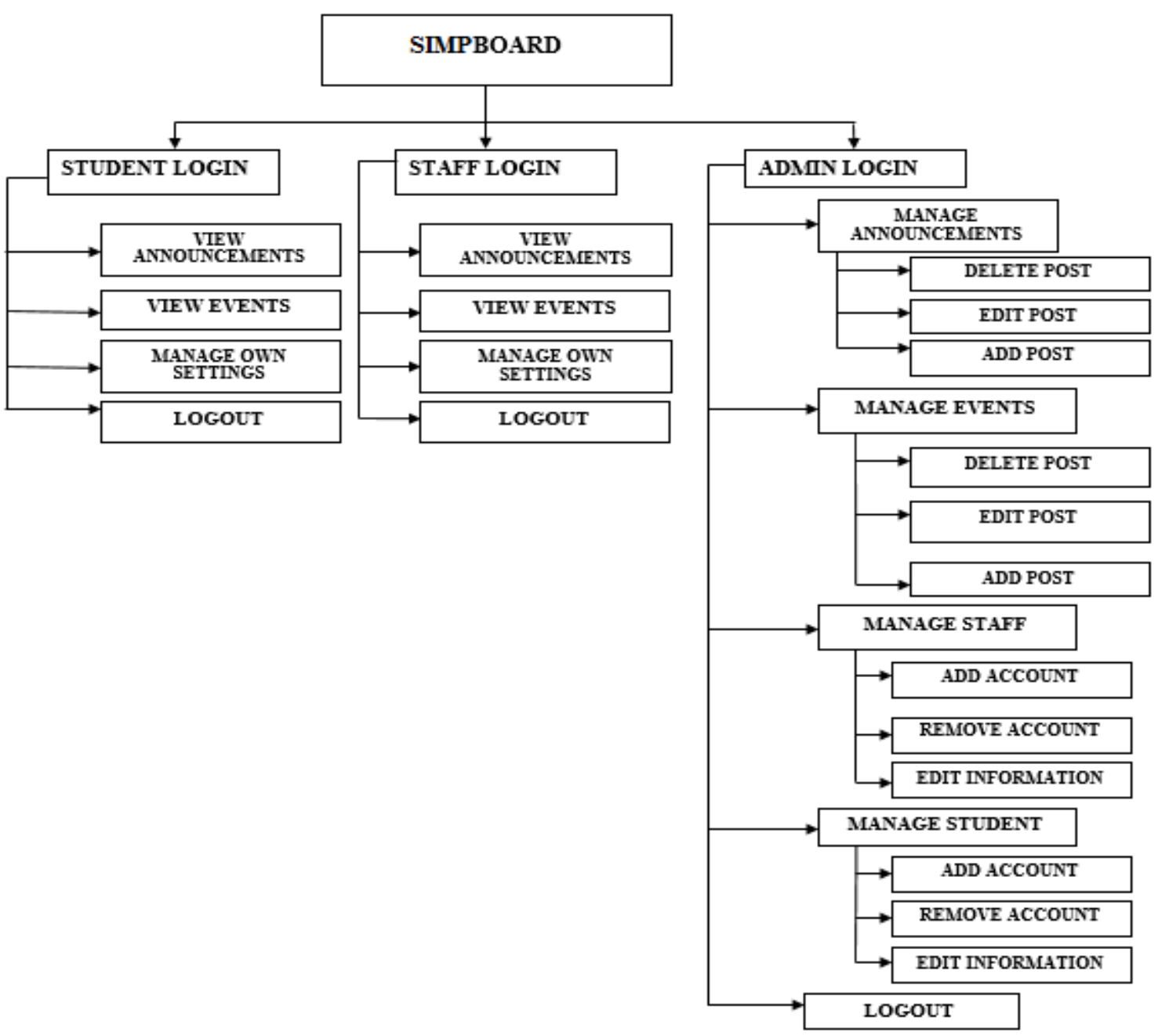

Figure 1: High level model of the proposed system

\subsection{Database Design}

The database design for the system is based on MongoDB. The differences between a typical SQL Database and MongoDB are depicted in Table 1.

\section{Table 1: SQL Database vs MongoDB Comparison}

\begin{tabular}{cc}
\hline SQL & MongoDB \\
\hline database & database \\
table & collection \\
row & document \\
column & Field \\
Primary key & Primary key \\
\hline
\end{tabular}

\section{EXPERIMENTAL RESULTS AND DISCUSSION}

This section gives a description of the experiments performed during the implementation phase of the proposed system. All experiments were carried out using Meteor JS (Meteor JavaScript) and MongoDB, and run on an Intel ${ }^{\circledR}$ Pentium $®$ CPU N3520 running Microsoft Windows 10 64-bit operating system, dual core $2.16 \mathrm{GHz}$ with $4.0 \mathrm{~GB}$ RAM.

\subsection{Sample Run}

The output of the experimentation of the proposed system is discussed in this section. There are two modules in this application namely the administrator and user modules respectively. Each of the modules can be invoked at the time of login. The login page serves as the default page of the application as shown in Figure 5. Existing users can login by supplying their login details while new users will have to register before they can have access to the application using the forms in Figures 6 and 7 respectively. The user can be a staff or student of the institution while the administrator serves as the super-user. All created accounts are displayed for activation by the administrator before they are accessible by the account owners (see Figure 8). This is to reduce and possibly eliminate the misuse of the SIMPBOARD application.

The administrator module is invoked when the login type is admin. This displays the admin panel as shown in Figure 9. 


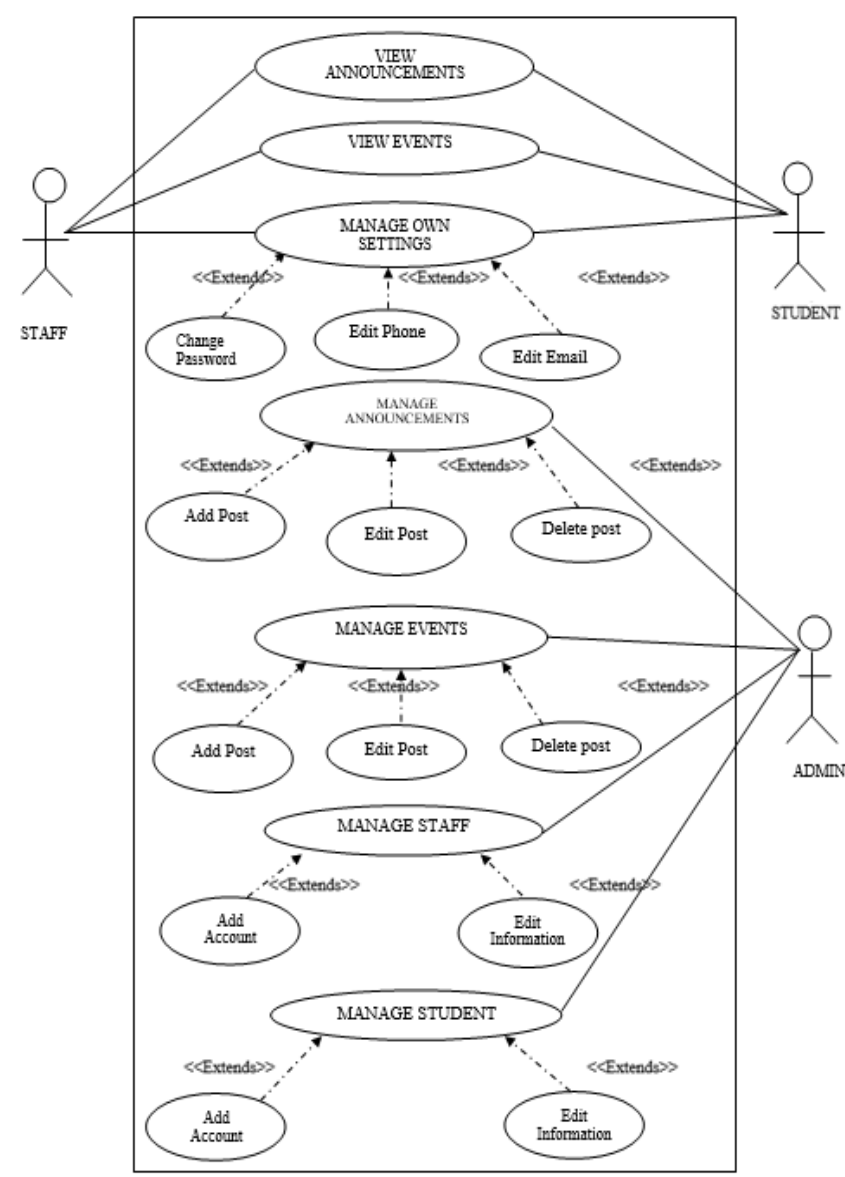

Figure 2. The use case diagram of the SIMPBOARD system

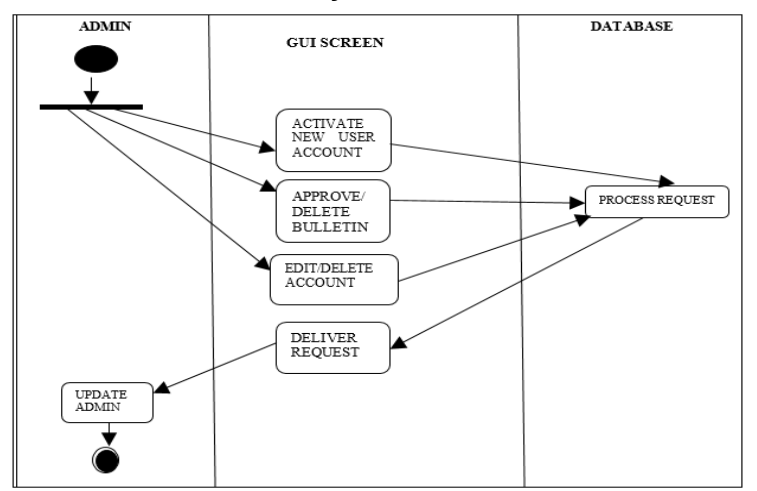

Figure 3. Activity diagram of the administrator's actions

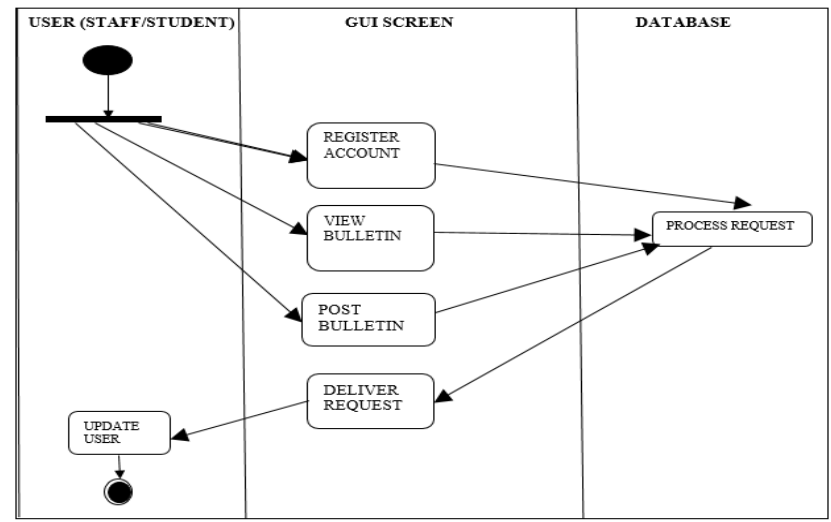

Figure 4. Activity diagram of the user's actions

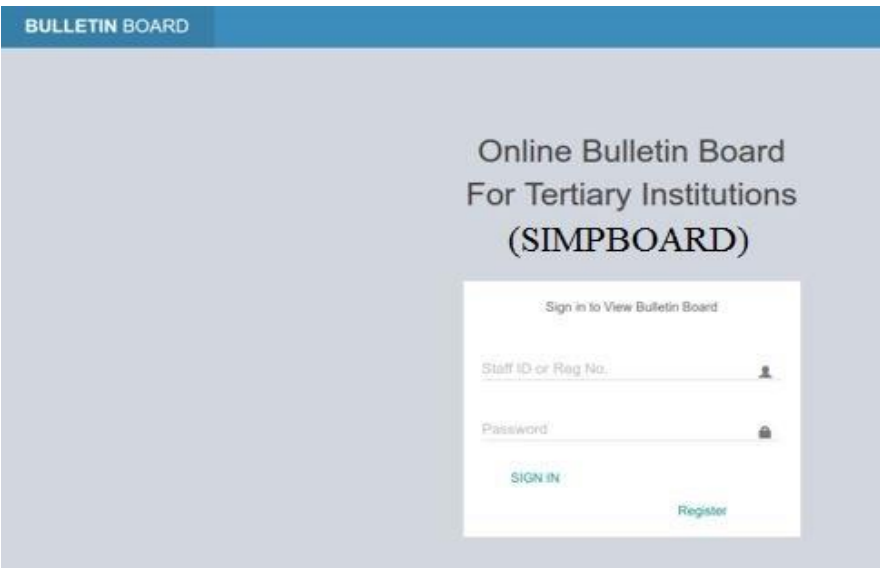

Figure 5. Login page for the SIMPBOARD application

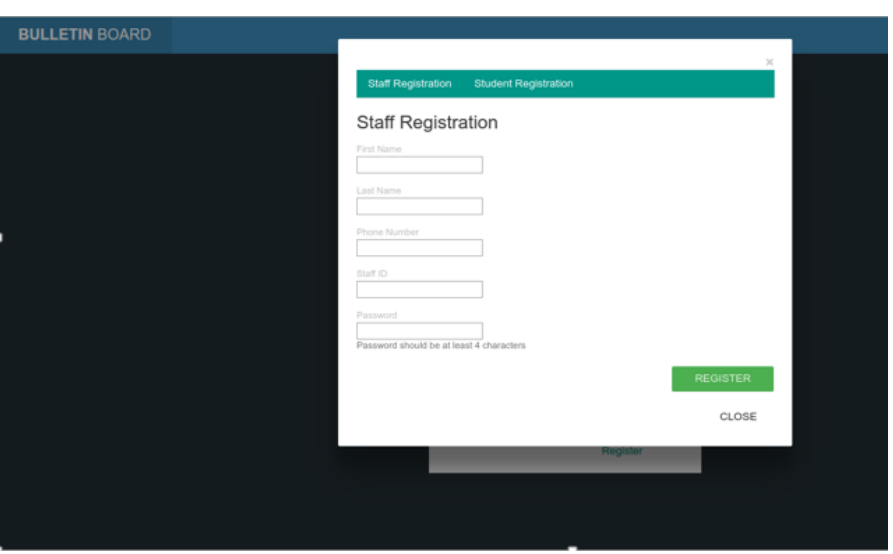

Figure 6. Staff registration page for the SIMPBOARD application

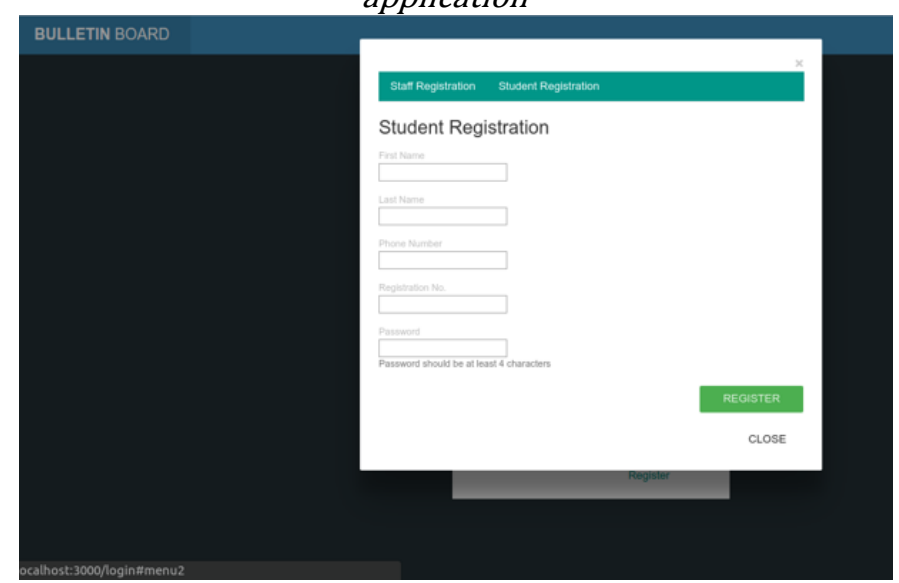

Figure 7. Student registration page for the SIMPBOARD

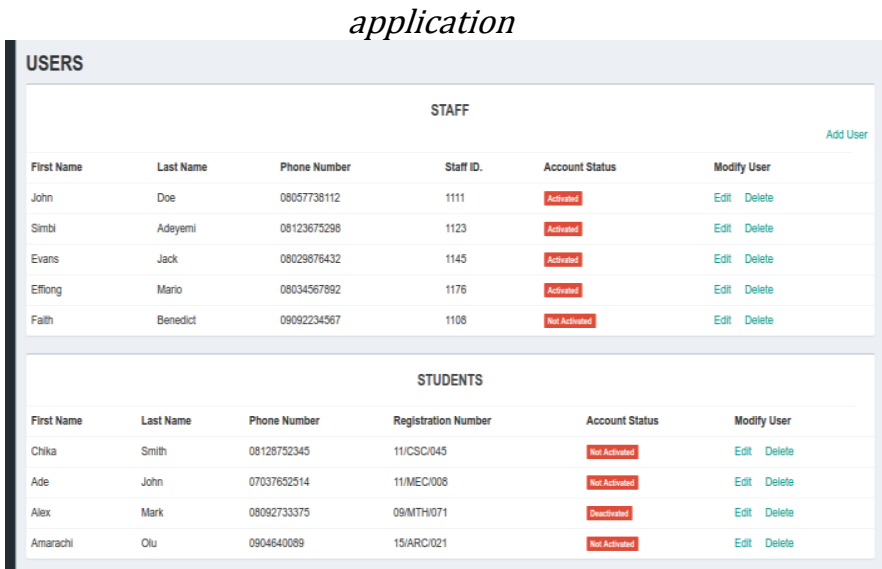

Figure 8. User activation page for SIMPBOARD 


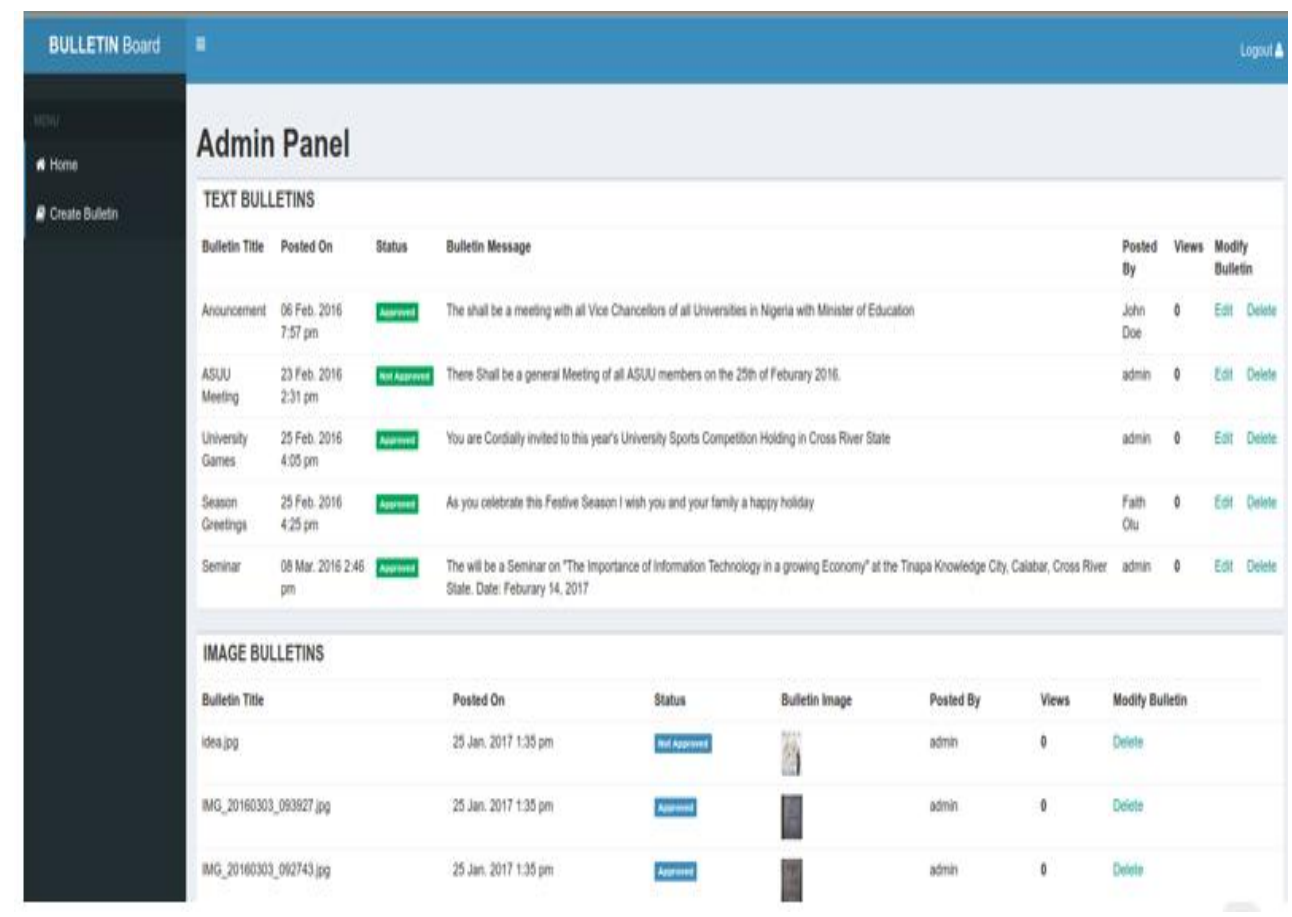

Figure 9. Administrator panel showing text and image bulletins

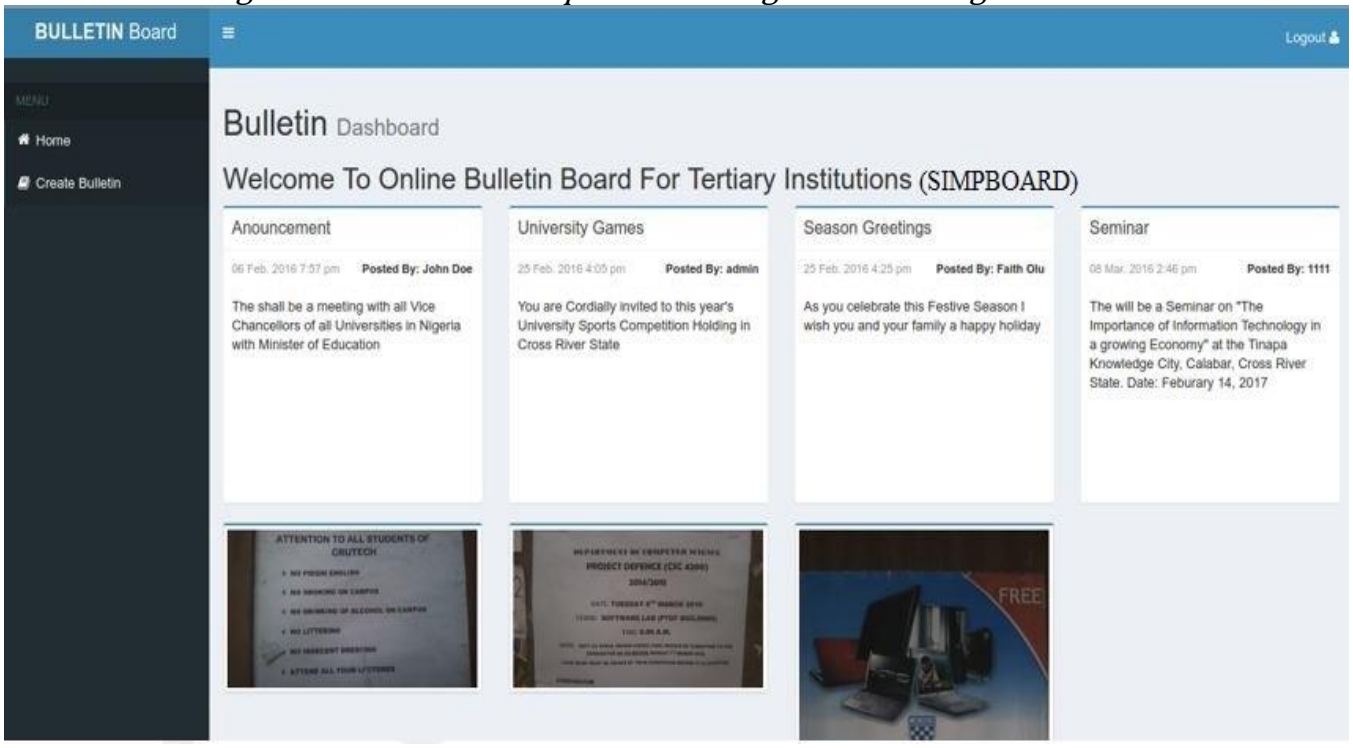

Figure 10. User's dashboard showing text and image bulletins

The admin panel displays all categories of bulletins including text and image bulletins. The bulletins created and sent by the users appear on the admin panel who has the prerogative to approve or disapprove the contents of the bulletins. The approved bulletins are then viewed by all users who have access to the application through the user's dashboard as shown in Figure 10. All new bulletins are created using the new bulletin page (see Figure 11 and Figure 12).

Text bulletins are created by entering the bulletin's title and message, and clicking the submit button as depicted in Figure 11. However, when the image bulletin option is selected, the new image bulletin can be uploaded for approval as shown in Figure 12.
All submitted bulletins can be edited before approval. This is achieved by clicking the edit option on the admin panel (see Figure 13). In the same vein, bulletins can be deleted when not suitable for publication or when no more in use with the delete option as depicted in Figure 14. This operation helps to keep a database of only relevant bulletins.

\subsection{Evaluation of the SIMPBOARD application}

SIMPBOARD provides an easy but efficient way of disseminating information in a tertiary institution without recourse to an increase in the computational complexity of the target machines. 


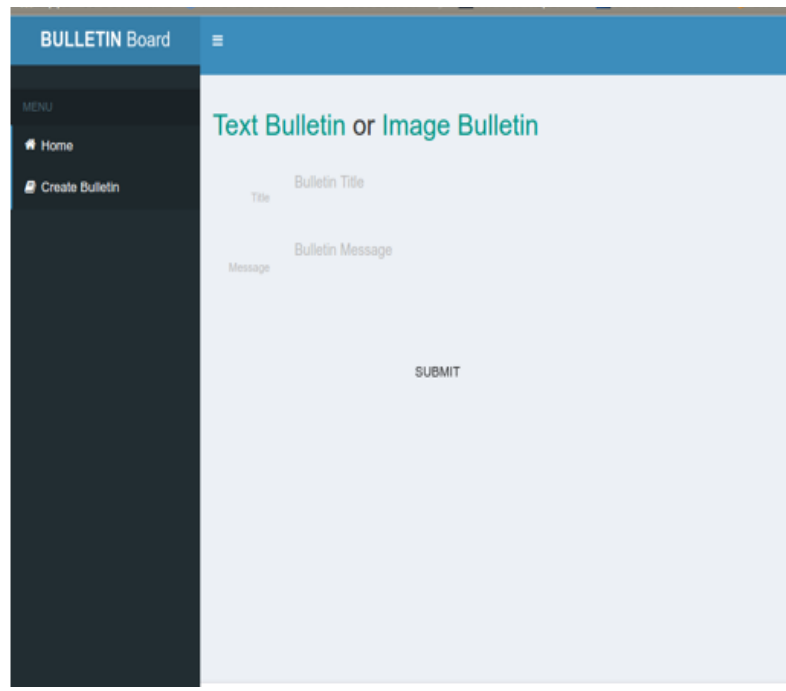

Figure 11. New bulletin creation page with the text bulletin option selected

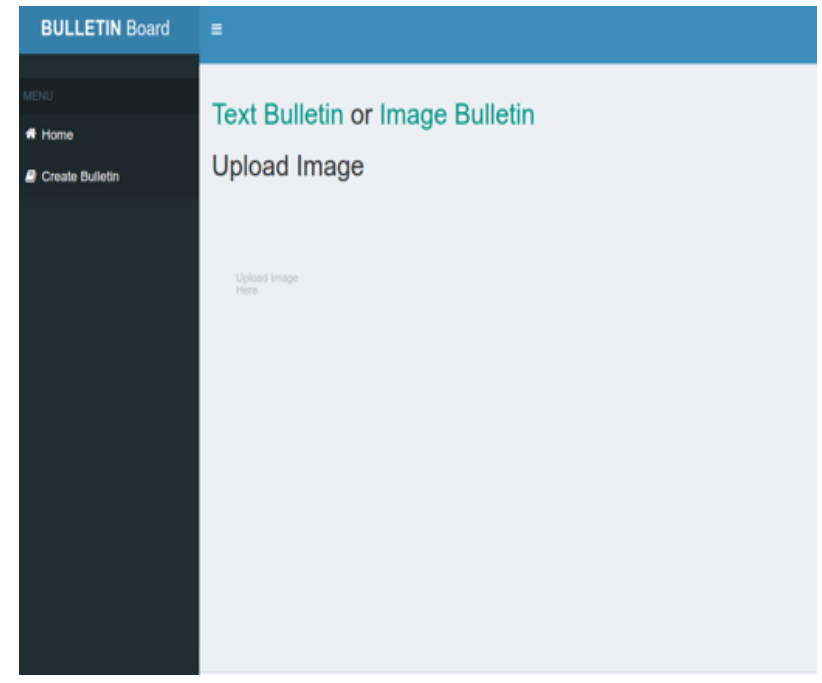

Figure 12. New bulletin creation page with the image bulletin option selected

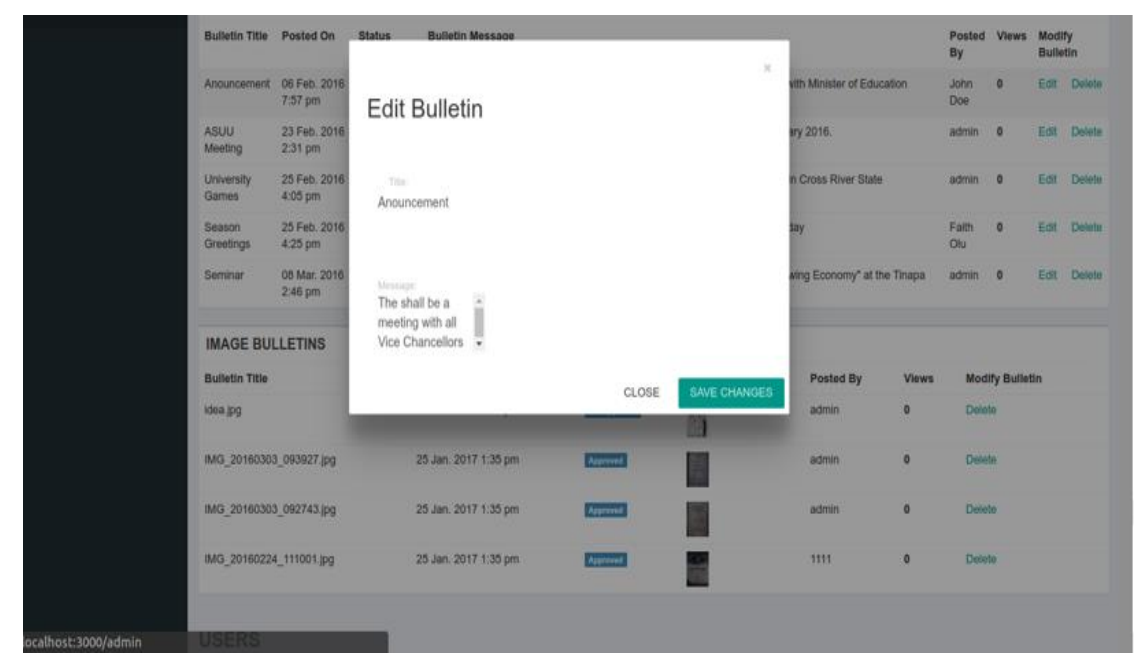

Figure 13. Editing a text bulletin before publication

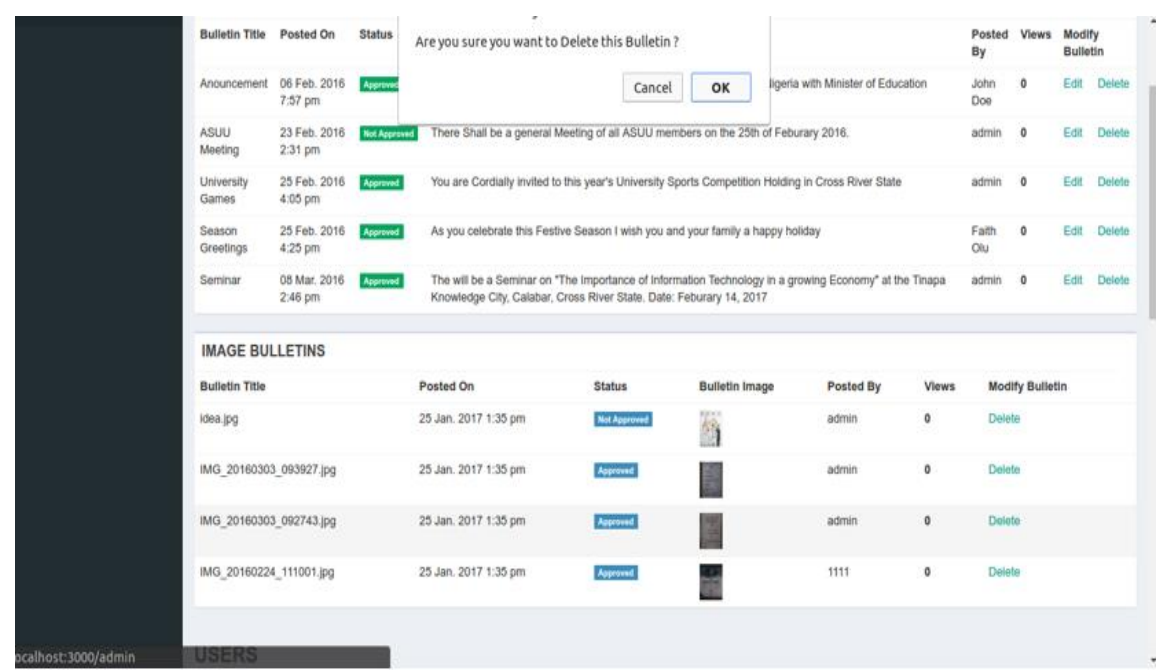

Figure 14. Using the delete option to erase a bulletin from the admin panel and database

Our application authenticates users, and the contents they post are scrutinized for prohibited words and images by an administrator before publication. Some of the existing online bulletin board systems are computationally expensive, and some are also proprietary with very specific system requirements [14]. However, SIMPBOARD uses MongoDB as its backend and can run on any Intel processor (as well as on 
smartphones) with minimum system requirements. Furthermore, MongoDB, which is a component of the MEAN (MongoDB, Express.js, Angular.js and Node.js) stack technology, stores data in JSON-like documents with dynamic schemas such that hierarchical relationships, arrays and other complex data structures can be stored easily. Information exchange with SIMPBOARD is fast and the latency for uploads and enduser access to bulletins is low.

\section{CONCLUSION}

The Online Bulletin Board system discussed in this work delivers an advanced means of passing information around an institution. It has the capability to disseminate information in a simple and well organized manner compared to the existing paper-based notice board system. With the use of the Online Bulletin Board, human traffic will be reduced at notice board locations, since information on notice boards can be accessed digitally on the web via any web browser. In addition, the security of bulletin placement is guaranteed as an administrator is assigned to validate information before been posted on the bulletin board. Generally, the Online Bulletin Board will become an improvement over the existing notice boards used in a tertiary institution for information dissemination, and will be a valuable platform for any institution interested in quick and reliable information exchange and access at all times.

\section{REFERENCES}

[1] Booch, G. The unified modeling language user guide. Pearson Education India, 2005.

[2] Johnson, G. "The relative learning benefits of synchronous and asynchronous text-based discussion", British Journal of Educational Technology, 39 (1), pp.166-169, 2008.

[3] Knight, T.O. and Gross, J. N., Prophet Financial Systems, Inc. "System and method for managing online message board”, U.S. Patent 6, 571,234, 2003.
[4] Ligorio, M.B. "Integrating communication formats: synchronous versus asynchronous and text-based versus visual", Computers \& Education, 37(2), pp.103-125. 2001.

[5] Li, Y. and Manoharan, S. "A performance comparison of SQL and NoSQL databases", In Communications, Computers and Signal Processing (PACRIM), 2013 IEEE Pacific Rim Conference, , pp. 15-19. 2013.

[6] Masoni, M., Guelfi, M. R. and Shtylla, J. "Computer mediated communication", In E-learning in Sanità, pp. 17-22. 2011.

[7] Parker, Z., Poe, S. and Vrbsky, S. V. “Comparing nosql mongodb to an sql db", In Proceedings of the 51st ACM Southeast Conference, p.5, 2013.

[8] Pena-Shaff, J. B. and Nicholls, C."Analyzing student interactions and meaning construction in computer bulletin board discussions", Computers \& Education, 42(3), pp.243-265, 2004.

[9] Rourke, L., Anderson, T., Garrison, D.R. and Archer, W. "Assessing social presence in asynchronous textbased computer conferencing", International Journal of E-Learning \& Distance Education, 14 (2), pp.5071. 2007.

[10] Rumbaugh, J., Jacobson, I. and Booch, G. Unified Modeling Language Reference Manual, The. Pearson Higher Education, 2004.

[11] Sung, K., Srinivasan, S. and Schulzrinne, H. "BBSONE: Bulletin board and forum system for mobile opportunistic networks", In Wireless Communications, Networking and Information Security (WCNIS), 2010 IEEE International Conference, pp. 371-376. 2010.

[12] Teibel, D.A. and Needham, B.H., Intel Corporation. "Method and apparatus for a bulletin board system”, U.S. Patent 6, , pp. 363 - 427, 2002.

[13] Thorne, S. L. Computer-Mediated Communication, In Encyclopedia of language and education, , pp. 1415-1426. Springer US. 2008.

[14] Wikipedia. "List of Bulletin Board Systems" https://en.wikipedia.org/wiki/List of bulletin boar d systems Accessed on April 1, 2017. 